\title{
Institutional and Socio-Economic Convergence in the European Union
}

\section{Jordi López-Tamayo}

AQR Research Group-IREA, Universitat de Barcelona, Spain

jlt_lopez@ub.edu

\section{Raul Ramos}

AQR Research Group-IREA, Universitat de Barcelona, Spain rramos@ub.edu

\section{Jordi Suriñach}

AQR Research Group-IREA, Universitat de Barcelona, Spain jsurinach@ub.edu
CroEconSur

Vol. 16

No. 2

December 2014

pp. 5-28

Received: September 17, 2014 Accepted: November 13, 2014 Research Article

doi:10.15179/ces.16.2.1

\section{Abstract}

The objective of this paper is to analyze convergence in institutional, social, and macroeconomic conditions between EU member states. Our analysis covers the period 1995-2013 and considers the potential impact of the Great Recession. With this aim, we use a composite indicator that combines information from 51 hard and soft indicators, and we estimate convergence equations for the composite indicator and its seven dimensions considering different country groups. The obtained results show evidence of conditional convergence among EU member states but limited evidence of unconditional convergence over the considered period.

Keywords: convergence, economic performance, social indicators, institutional quality, European Union

JEL classification: $\mathrm{C} 43, \mathrm{~F} 62, \mathrm{O} 43$ 


\section{Introduction and Objectives ${ }^{1}$}

Economic and social cohesion are two of the main objectives of the European Union (EU). In fact, the Europe 2020 strategy, launched in 2010, tries to address the shortcomings of the European growth model by creating the conditions for smart, sustainable, and inclusive growth. In particular, priorities have been set not only in economic outcomes but also in other aspects related to the following: employment; research and development; climate/energy; education; social inclusion; and poverty reduction. However, after the different enlargements of the EU and several decades of impressing outcomes (see Gill and Raiser, 2012), the fact that due to the Great Recession, convergence among EU member states has probably slowed - and even reversed in some parts of Europe - has been recently recognized by the European Commission (2014).

In this context, while economic convergence, usually measured as gross domestic product (GDP) per capita convergence, has attracted significant academic attention (Borsi and Metiu, 2013), studies on institutional and social convergence within the European Union from a wide perspective are relatively scarce. In fact, the main limitation for EU-level analysis is data availability and comparability; therefore, most researchers focus on individual country studies. One example of this literature is Liargovas and Fotopoulas (2009) who analyzed the socioeconomic convergence between Greek regions. Some notable exceptions are Rodriguez-Pose and Tselios (2013) who analyze EU convergence trends in social welfare or Savoia and Sen (2012) who consider convergence in institutions.

Our paper contributes to this literature from two perspectives: first, we take advantage of a recently developed composite indicator (López-Tamayo et al., 2014) that permits us to analyze convergence in institutional, social, and macroeconomic conditions in a wide sample of countries, including the $28 \mathrm{EU}$ member states. The use of composite indicators to compare different dimensions between developed and emerging economies (and even within them) is not

1 The research leading to these results has received funding from the European Community's Seventh Framework Programme (FP7/2010-2.2-1) under grant agreement no. 266834. 
straightforward. The literature is currently expanding this view not only in economic terms but also in social and institutional dimensions; for instance, see Giambona and Vasallo (2014) or Çolak and Ege (2013). In fact, the methodology developed by López-Tamayo et al. (2014) adds to the growing literature that tries to overcome the shortcomings of unidimensional approaches such as those focusing on Gross Domestic Product per capita, those based on a wide set of variables ${ }^{2}$, or those based on a multidimensional index such as the United Nations' Human Development Index that has been widely criticized in the literature (e.g., Wu et al., 2014). This composite indicator allows us to analyze the comparative situation among countries considered from different dimensions. The wider perspective in the construction of the index allows us to focus on very different questions using a homogeneous dataset. For instance, the overall index can be used to analyze the pros and cons of a particular policy that attempts to attract foreign direct investment from an economic point of view; but at the same time it can also analyze the impact on institutional and social aspects (e.g., related to the functioning of the labor market once foreign investors have entered the country).

The second contribution of our research is related to the fact that our analysis covers the period between 1995 to 2013. This period permits us to consider the impact of the Great Recession in different considered dimensions by analyzing the impact of the business cycle on convergence trends comparing the two subperiods before and during/after the crisis. Although the convergence process predicted by the neoclassical model occurs in the long run, as suggested by Beyaert and García-Solanes (2014), short-run conditions can affect long-run convergence through different channels. For instance, if during an expansionary phase, and thanks to the improvement in public finances, public research and development (R\&D) investments increase; this will not only contribute to shortterm improvement of the economy but also to long-run productivity, increasing the speed of convergence. The main assumption is that the convergence process

2 For instance, Niroomand and Nissan (2007) analysed socio-economic gaps between EU countries considering 45 different variables but not simultaneously. 
is non-linear and that countries with different short-run conditions could deviate from the long-run trend towards convergence.

The rest of the paper is structured as follows. First, the methodology used in the study and details on data sources and variable definitions are provided in the next section. The empirical results are shown in the third section, and the paper concludes by summarizing the main findings.

\section{Data Sources and Methodological Issues}

Our analysis of socio-economic and institutional convergence in the European Union is based on the Institutional, Social, and Economic Performance Index (ISEPI) developed by López-Tamayo et al. (2014). The ISEPI is built from 51 variables that comprise both hard and soft data (Figure 1), and it comprises the following seven main sub-indexes that try to consider identified, measurable, and comparable socioeconomic aspects that are relevant from a global perspective.

- Macroeconomic environment (I1): This sub-index measures the economic environment of the country. It takes into account GDP, labor, public accounts, investment, international trade, and financial issues.

- Costs and prices (I2): This sub-index considers different variables related to prices and costs, including consumer prices, labor costs, hourly wages, cost of living and exchange rates.

- Productivity and human capital (I3): This sub-index summarizes different aspects related to labor productivity and the level of human capital of every country, including schooling levels, availability of qualified workers, among others.

- Technological and innovative capacity (I4): This sub-index covers the aspects related to the technological capacity of the country as well as the 
efforts to improve it. Therefore, we take into account the technological capacity as well as different measures of technological adoption.

- Business-friendly environment (I5): This sub-index covers aspects related to factors helping or hindering business activity in a country. We take into account the quality of infrastructures, different measures of investment risks, administrative burdens, barriers to international trade, and taxes on firms.

- Quality of life and labor market conditions (I6): This sub-index captures life expectancy, quality of life, working conditions (i.e., workers' motivation and hours of work), and security (i.e., personal security and private property protection).

- Market potential (I7): The last sub-index captures the economic potential of a country from an economic point of view and covers demand in terms of population and growth potential.

The ISEPI index and the seven sub-indexes are valued on a 0-7 scale where 0 is assigned to the minimum value and 7 to the maximum value across countries and time-periods. So, a higher value of the index indicates a better relative performance in the considered dimension. More details on the methodology for building the ISEPI index and the seven sub-indexes can be found in LópezTamayo et al. (2014).

While each of the sub-indexes has a clear direct interpretation, the overall index is built as a simple average of the different dimensions. Note that the authors provide some robustness checks to different weight schemes including multivariate statistical techniques such as principal component analysis. According to LópezTamayo et al. (2014) the ISEPI index combines elements that are directly related to the external competitiveness of an economy, to the capacity to attract foreign investors, and to the quality of life and welfare of citizens. 
Several databases were used to gather data regarding the 51 considered indicators, including the following: the World Bank World Development Indicators, the World Investment Report by the United Nations Conference on Trade and Development, The International Institute for Management Development datasets, and additional variables from the Conference Board and The World Economic Forum datasets. The period considered is 1995-2013, and data is provided for 77 countries including a wide sample of economies: the most competitive economies according to the World Economic Forum, the 28 members of the European Union, and several emerging economies. The final sample of countries is formed by the set of 77 countries listed in table A1.

In order to assess whether a convergence process in the ISEPI and its seven subindexes have been observed between 1995 and 2013, we start with the analysis of the evolution of the standard deviation of the ISEPI, which is the usual tool to check for sigma-convergence. Next, we continue our analysis with an unconditional $\beta$-convergence analysis running the following a la Barro and Salai-Martin (2003) regression:

$g_{i}=\alpha+\beta I_{0, i}+C_{i}$.

where $g$ denotes the annualized growth rate between 1995 and 2013 of the considered index, $I_{0}$ represents its initial value, and $C_{i}$ is an error term that captures common transitional shocks for all countries. The parameter $\beta$ captures the speed of convergence into a unique steady-state and is assumed to be common to all countries involved in the analysis. Equation (1) is also estimated for two different sub-periods analyzing convergence between 1995 and 2007 (pre-crisis) and 2007 and 2013 (during/after the crisis).

In order to evaluate if convergence to a country-specific steady state is observed in the considered period, we next run the following conditional $\beta$-convergence regression for the ISEPI and the different sub-indexes under a panel data framework: 


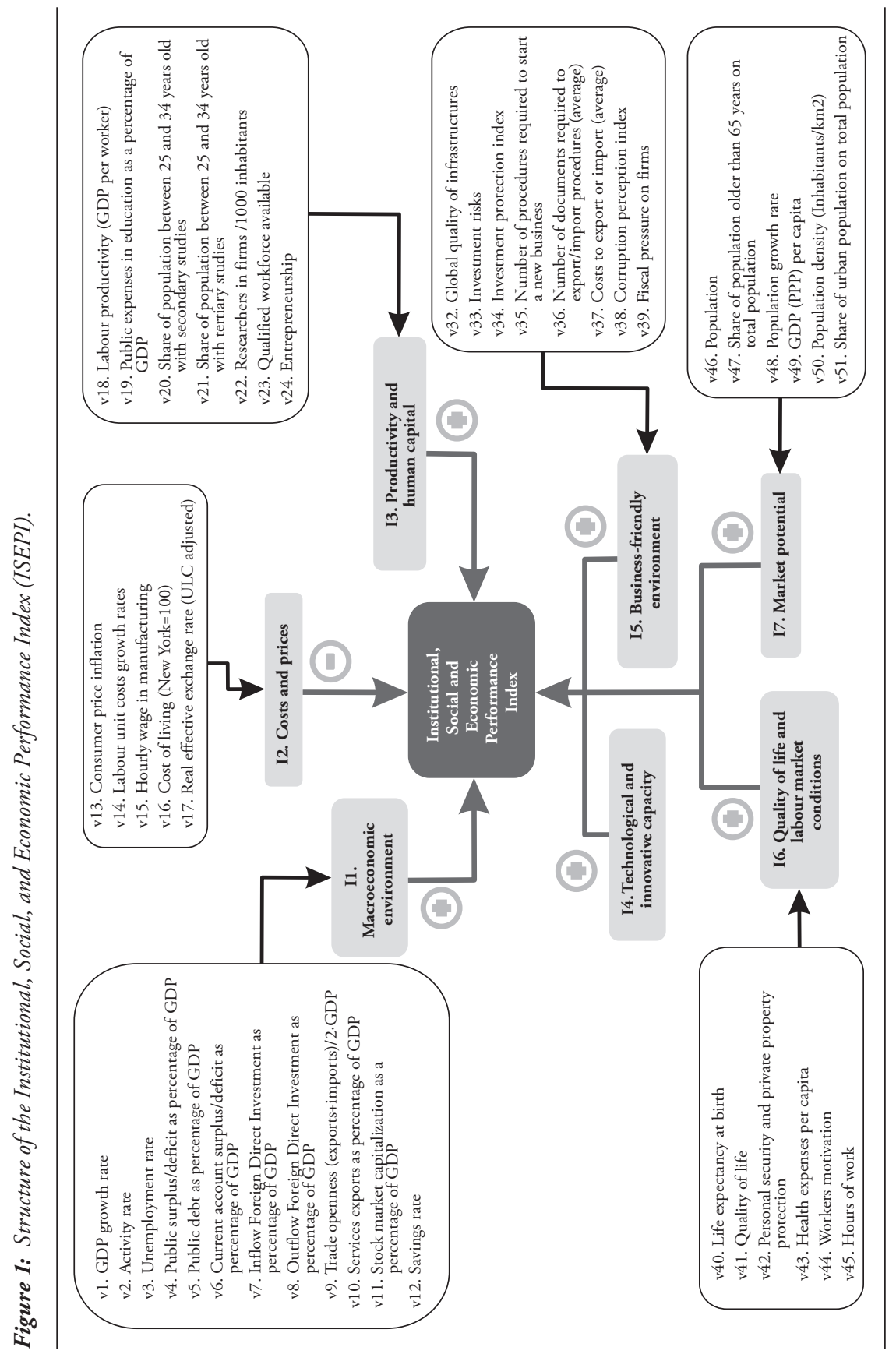


$g_{i t}=I_{0, i t} \beta+Z_{i}+T_{t}+C_{i t}$.

where $g_{\text {it }}$ represents the annual growth rate of each index, $I_{0, i t}$ the initial values of each index, $Z_{i}$ and $T_{t}$ denote, respectively, country and time specific fixed effects, and lastly $\epsilon_{i t}$ is a random error term. As before, Equation (2) is estimated for the whole period (1995-2013) and for two sub-periods (1995-2007 and 2008-2013). The validity of the assumption in relation to the structural break point is assessed by Chow tests.

The results of this empirical analysis are shown in the next section.

\section{Empirical Results}

Table 1 shows the 2013 ranking for the 77 considered countries according to the values of the ISEPI. If we look at the top positions with values of the ISEPI higher than 4.5 points, we find Singapore (1st, 5.33), Luxembourg (2nd, 4.79), Sweden (3rd, 4.64), Finland (4th, 4.59) and Denmark (5th, 4.55). Other EU member states are also located in the upper part of the table like the Netherlands, Ireland, Belgium, Austria, Germany, United Kingdom, and France that are within the first 20 positions. Slovenia, Estonia, Malta, Czech Republic, Spain, Lithuania, Portugal, Italy, Poland, Cyprus, Latvia, Slovakia, and Greece follow in the rankings. The last positions are covered by developing African countries such as Angola (75th, 1,99), Tanzania (76th, 1.99), and Nigeria (77th, 1.91).

Figure 2 shows the unweighted average value of the ISEPI in 1995 and 2013 for the $28 \mathrm{EU}$ member states and the ten more competitive economies (not in the EU) according to the World Economic Forum report (in alphabetical order, Australia, Canada, Japan, Korea, Qatar, Saudi Arabia, Singapore, Switzerland, United Arab Emirates and the United States of America). From this figure, it is clear that on average EU member states are lagging behind the more competitive world economies. 
Table 1: Country Ranking According to the ISEPI Index for 2013

\begin{tabular}{|c|c|c|c|c|c|}
\hline Country & ISO & ISEPI & Country & ISO & ISEPI \\
\hline Singapore & SGP & 5.33 & Jordan & JOR & 2.78 \\
\hline Luxembourg & LUX & 4.79 & West Bank and Gaza & PSE & 2.78 \\
\hline Sweden & SWE & 4.64 & Mexico & MEX & 2.76 \\
\hline Finland & FIN & 4.59 & Turkey & TUR & 2.76 \\
\hline Denmark & DNK & 4.55 & Kazakhstan & KAZ & 2.72 \\
\hline Netherlands & NLD & 4.49 & Libya & LBY & 2.71 \\
\hline Switzerland & $\mathrm{CHE}$ & 4.47 & China & $\mathrm{CHN}$ & 2.71 \\
\hline Ireland & IRL & 4.43 & Tunisia & TUN & 2.66 \\
\hline United States of America & USA & 4.40 & Lebanon & LBN & 2.65 \\
\hline Israel & ISR & 4.34 & Viet Nam & VNM & 2.62 \\
\hline Belgium & BEL & 4.26 & Azerbaijan & $\mathrm{AZE}$ & 2.61 \\
\hline Austria & AUT & 4.24 & Philippines & PHL & 2.61 \\
\hline Canada & CAN & 4.20 & Russian Federation & RUS & 2.61 \\
\hline Korea, Republic of & KOR & 4.19 & Croatia & HRV & 2.60 \\
\hline Germany & DEU & 4.09 & Morocco & MAR & 2.58 \\
\hline Japan & JPN & 4.08 & Georgia & GEO & 2.56 \\
\hline Australia & AUS & 3.97 & Armenia & ARM & 2.51 \\
\hline United Kingdom & GBR & 3.97 & Argentina & ARG & 2.48 \\
\hline France & FRA & 3.95 & Brazil & BRA & 2.48 \\
\hline Malaysia & MYS & 3.74 & Colombia & COL & 2.48 \\
\hline United Arab Emirates & $\mathrm{ARE}$ & 3.70 & Bulgaria & BGR & 2.47 \\
\hline Slovenia & SVN & 3.60 & Indonesia & IDN & 2.47 \\
\hline Estonia & EST & 3.60 & Peru & PER & 2.46 \\
\hline Qatar & QAT & 3.55 & Moldova & MDA & 2.41 \\
\hline Malta & MLT & 3.50 & Romania & $\mathrm{ROU}$ & 2.40 \\
\hline Czech Republic & CZE & 3.39 & Egypt & EGY & 2.32 \\
\hline Spain & ESP & 3.35 & South Africa & ZAF & 2.32 \\
\hline Lithuania & LTU & 3.34 & Algeria & DZA & 2.31 \\
\hline Saudi Arabia & SAU & 3.26 & Belarus & BLR & 2.31 \\
\hline Portugal & PRT & 3.26 & Ukraine & UKR & 2.27 \\
\hline Italy & ITA & 3.21 & Iran, Islamic Republic of & IRN & 2.26 \\
\hline Chile & CHL & 3.21 & Senegal & SEN & 2.20 \\
\hline Poland & POL & 3.15 & Syrian Arab Republic (Syria) & SYR & 2.18 \\
\hline Cyprus & CYP & 3.10 & India & IND & 2.08 \\
\hline Hungary & HUN & 3.08 & Kenya & KEN & 2.03 \\
\hline Thailand & THA & 3.07 & Angola & $\mathrm{AGO}$ & 1.99 \\
\hline Latvia & LVA & 3.07 & Tanzania, United Republic of & TZA & 1.99 \\
\hline Slovakia & SVK & 2.94 & Nigeria & NGA & 1.91 \\
\hline Greece & GRC & 2.85 & & & \\
\hline
\end{tabular}


However, the comparison between 1995 and 2013 also permits us to conclude that the evolution in the last two decades has been quite similar. In order to avoid potential biases in the comparison due to the consideration of only the initial and the final year in our sample, Figure 3 shows the same information for each considered year. The observed patterns are quite similar to the ones described in Figure 2. In fact, nearly parallel trends are observed between the two groups of countries.

Figure 2: Average Value of the ISEPI in 1995 and 2013 (Selected Countries' Groups)

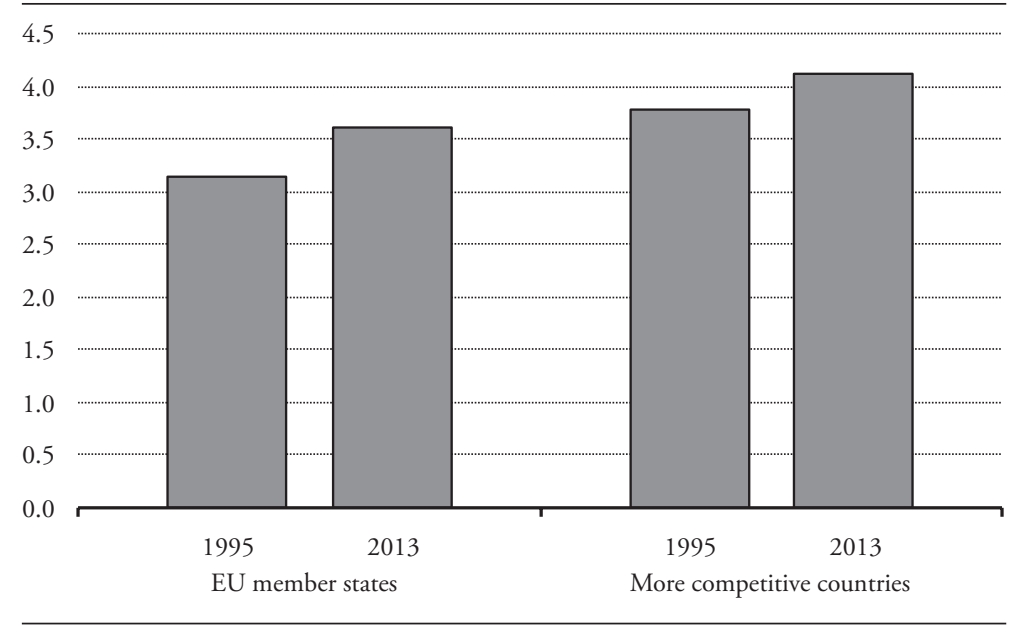

Source: Authors' calculations.

Figure 4 shows the evolution between 1995 and 2013 of the standard deviation of the ISEPI, the usual tool to check for sigma-convergence. As we can see, disparities among EU member states increased during the first years of the analyzed period, but they remained fairly stable during the rest of the period. The standard deviation increased from values around 0.55 in 1995 to 0.7 in 2013, although it has halted after 2000. The trend is very different from the one observed among the ten more competitive world economies, where the initial value of the standard deviation was much higher than the value observed for the EU member states (close to 0.8 in the mid-90s), and the final values are below 0.6. 
Figure 3: Evolution of ISEPI Between 1995 and 2013 (Selected Countries' Groups)
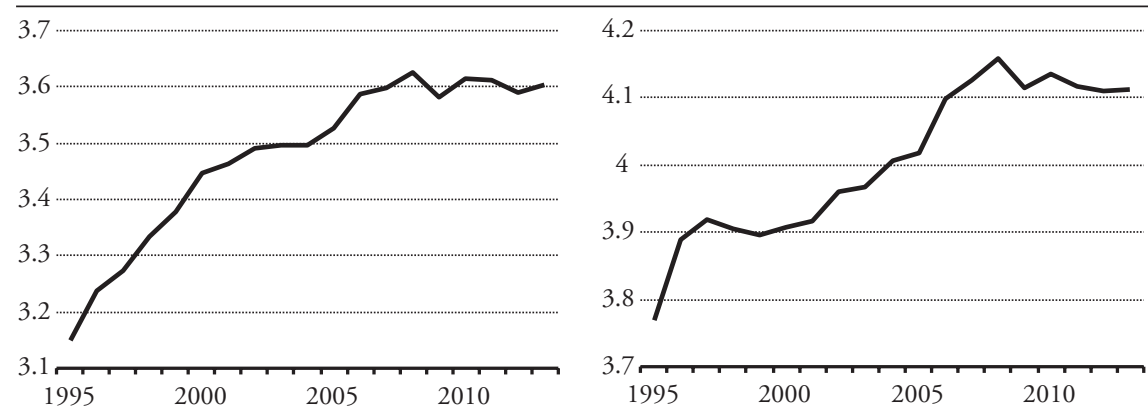

Source: Authors' calculations.

A similar conclusion is obtained when annualized growth rates of the ISEPI between 1995 and 2013 are regressed on the initial levels. In the first panel of Figure 5, we can see that there is a clear convergence trend that is not appreciated when the $28 \mathrm{EU}$ member states are considered (second panel). In fact, the evidence shown in this panel of the figure clearly points to the existence of convergence clubs between the EU member states. While old EU member states seem to converge to a higher ISEPI value and are part of the best position club (with the exception of Mediterranean countries), new member states from central and eastern Europe form a second club; however, Romania, Bulgaria, and Croatia do not seem to be included.

Figure 4: Sigma-Convergence (ISEPI Standard Deviation) - Selected Countries' Groups
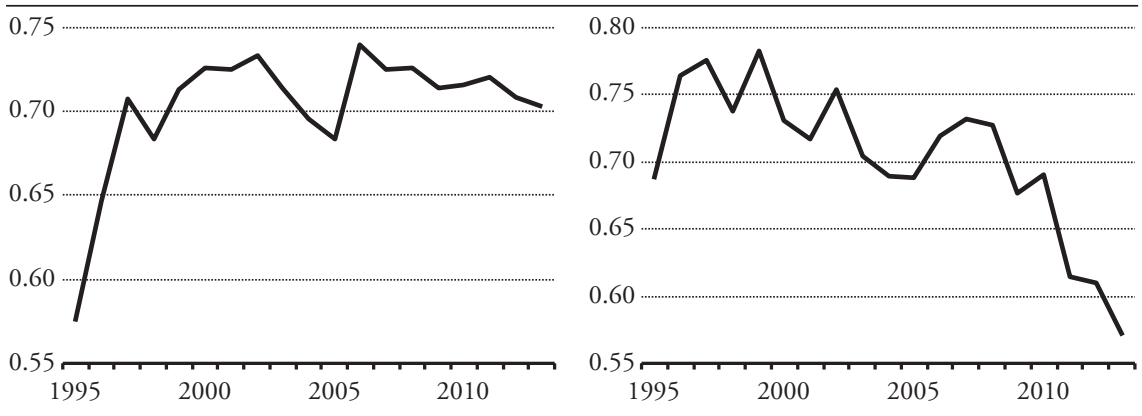

Source: Authors' calculations. 
Figure 5: Unconditional Beta-Convergence - Selected Countries' Groups
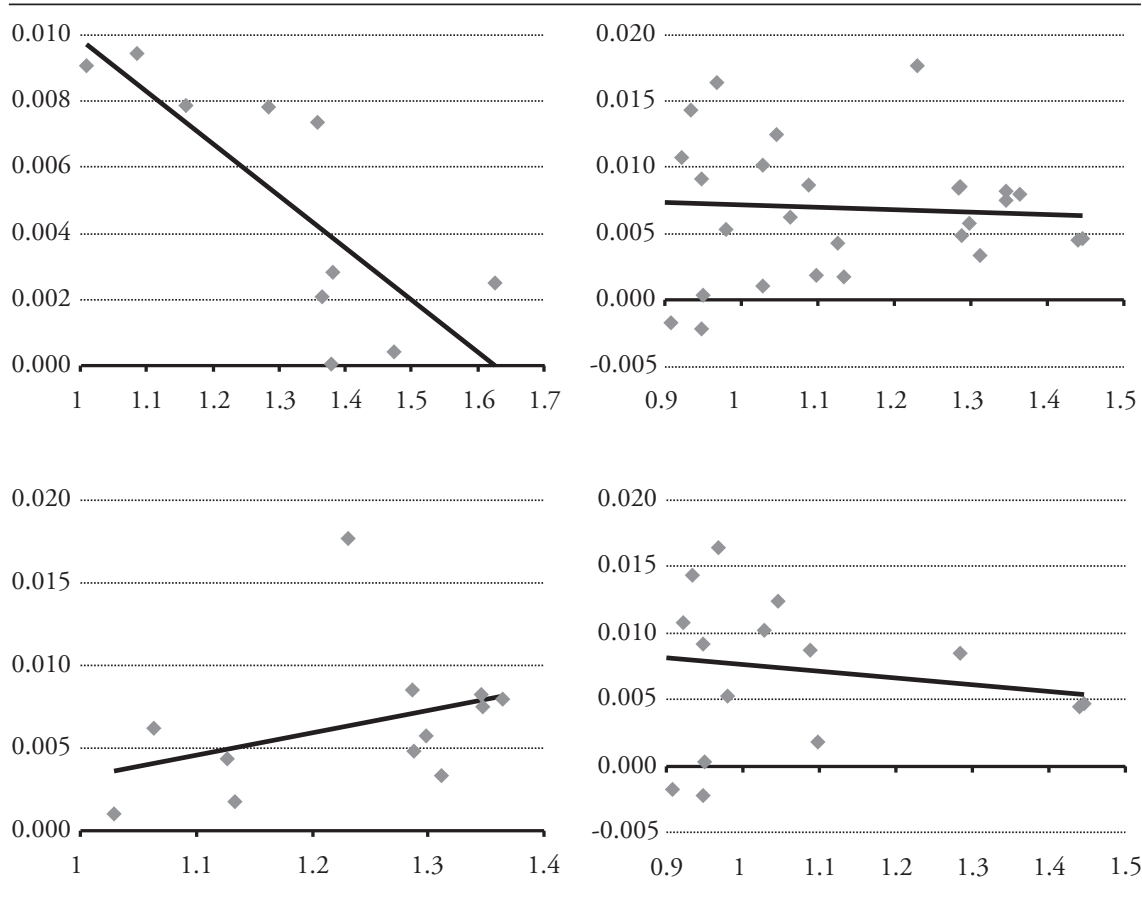

Source: Authors' calculations.

Table 2 shows the results of estimating beta-convergence regressions using a cross-sectional specification (unconditional convergence). The results from the cross-sectional specification are related to unconditional convergence. Under this framework, it is assumed that countries are converging to the same steady-state (i.e., long-run levels will be the same for each country) and, for this reason, in case of convergence, countries with lower initial levels need to grow faster than the others in order to catch up.

Each row shows the result of a different variable; it starts with the ISEPI and is followed by the rest of the sub-indexes. The first column of the table shows the results for the $28 \mathrm{EU}$ member states; the second column shows the results 
for the EU old member states; the third column shows results for the EU new member states; and the fourth column shows the results for the more competitive economies. For each group of countries and indicator, results are provided for three different periods: the first column shows the results for the annualized growth in the considered indicator between 1995 and 2013 compared to the initial value in 1995; the second column shows the results for the annualized growth in the considered indicator between 1995 and 2007 compared to the initial value in 2007; and the last column shows the results for the annualized growth in the considered indicator between 2007 and 2013 compared to the initial value in 2007.

From this table, and starting with the ISEPI, we can see that this scenario is only observed for the more competitive economies, is driven by the behavior of these economies during/after the crisis. The same is valid for sub-indexes related to productivity and business-friendly environment. However, convergence processes in cost and prices and technological and innovative capacity have been negatively affected by the worst short-run conditions.

Similar results are obtained for the 28 EU member states where unconditional (or absolute) convergence is only observed for the sub-indexes related to "Technological and Innovative capacity" and "Business friendly environment", but not for the overall index. It is worth mentioning that the analysis by subperiods shows changes in the convergence dynamics in relation to costs and prices (where the more recent data show a more similar evolution between considered countries) and market potential (where the opposite result is observed).

Our estimates also show convergence among new EU member states for nearly all sub-indexes except "Productivity and human capital" and "Business friendly environment". However, absolute convergence is only observed during the second sub-period in macroeconomic conditions and costs and prices. 


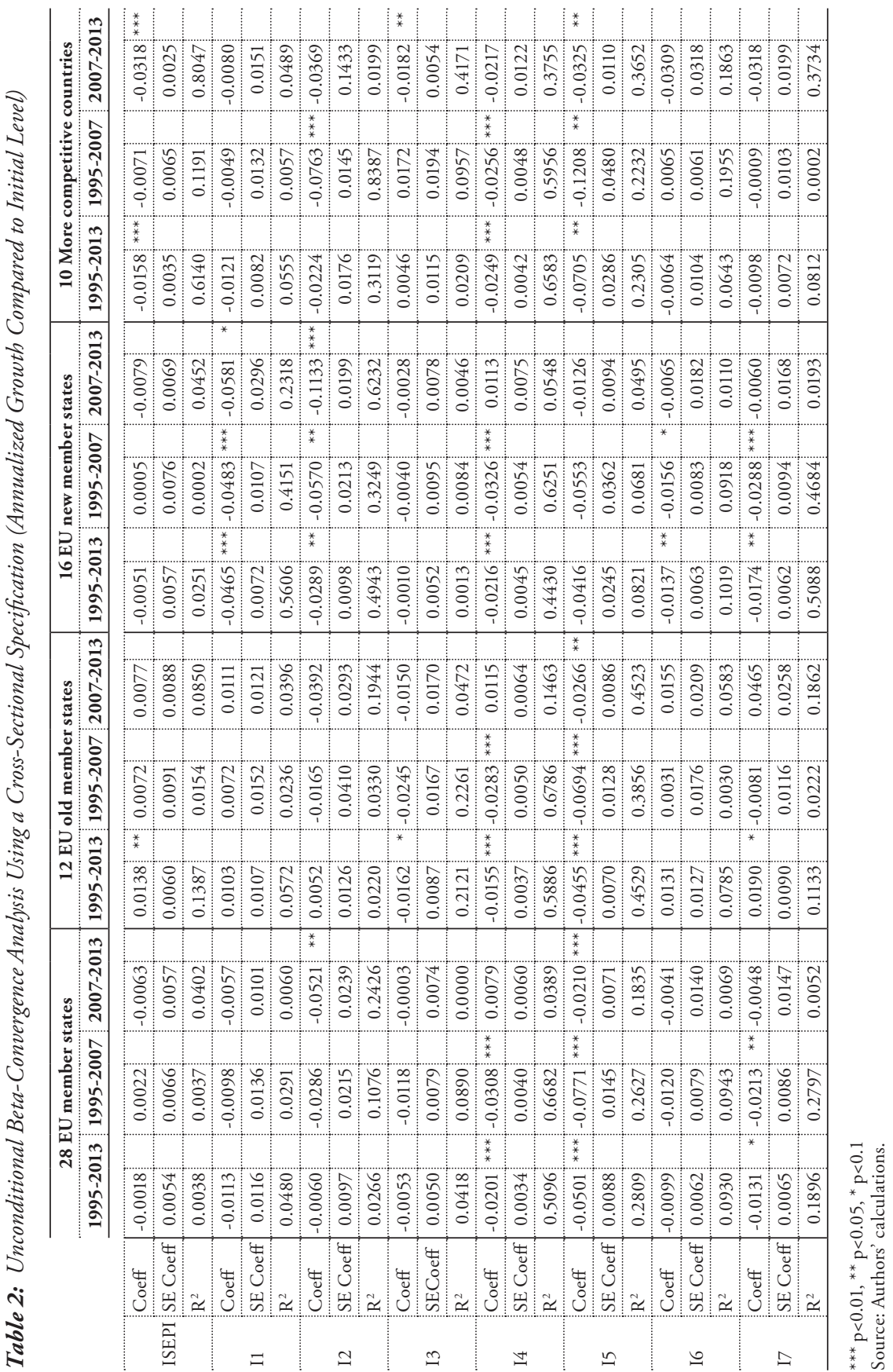


Tables 3 and 4 show the results of analyzing $\beta$-convergence in a panel data framework. As previously mentioned, the main difference from the previous specification is that we now assume convergence to country-specific steady states. Table 3 shows the results for the whole period (1995-2013), while table 4 presents the results by sub-periods (1995-2007 and 2008-2013). As before, the results are shown for the overall index and the different sub-indexes and for the four groups of considered economies. When moving to the analysis of the panel specification, there are two relevant differences from the previous analysis: first, the values of the estimated coefficients are significantly higher than in the previous specification; second, convergence is observed in nearly all the considered cases. Regarding the first result, as highlighted by Islam (1995), the natural rate of convergence in a panel data setup is substantially higher than usual values obtained in a crosssectional framework. A similar result is found in the meta-analysis by Abreu et al. (2005); panel data usually provide a speed of convergence for GDP per capita three times higher than cross-sectional specifications. Our results are not an exception to previous findings in the literature. Regarding the second result, the main explanation is that once time and country fixed effects are included in the specification, we are no longer analyzing unconditional (or absolute) convergence; instead we are analyzing conditional convergence. Conditional convergence is defined as the existence of an inverse relationship between the initial level of the analyzed variable and its subsequent growth once the determinants of the steady-state level of the variable are controlled for. In our case, countries with low levels of the steady state of the ISEPI (or the different sub-indexes) do tend to grow more rapidly; however, this does not mean that all countries in each group converge to the same steady state. It only implies that they are converging to their own steady states, while under the unconditional convergence, differences will be transitory. Conditional convergence implies that differences may be permanent due to cross-country structural factors. 
Table 3: Conditional Convergence Between 1995 and 2013 (Panel Specification With Time and Country Fixed Effects Included)

\begin{tabular}{|c|c|c|c|c|}
\hline ISEPI & EU & EU-old & EU-new & Competitive \\
\hline Coefficient & -0.390 & -0.199 & -0.507 & -0.159 \\
\hline SE Coeff. & 0.001 & 0.001 & 0.003 & 0.002 \\
\hline $\mathrm{R}^{2}$ & 0.274 & 0.399 & 0.318 & 0.202 \\
\hline Obs. & 504 & 216 & 288 & 180 \\
\hline F-test & 2.555 & 2.426 & 2.729 & 1.245 \\
\hline p-value & 0.001 & 0.002 & 0.000 & 0.237 \\
\hline Hausman & 131.514 & 34.587 & 99.418 & 9.209 \\
\hline p-value & 0.000 & 0.011 & 0.000 & 0.955 \\
\hline Chow & 1.497 & 2.882 & 1.541 & 1.468 \\
\hline p-value & 0.047 & 0.001 & 0.076 & 0.142 \\
\hline
\end{tabular}

\begin{tabular}{|c|c|c|c|c|}
\hline I1 & EU & EU-old & EU-new & Competitive \\
\hline Coefficient & -0.283 & 0.069 & -0.451 & -0.134 \\
\hline SE Coeff. & 0.001 & 0.002 & 0.003 & 0.002 \\
\hline $\mathrm{R}^{2}$ & 0.231 & 0.294 & 0.331 & 0.212 \\
\hline Obs. & 502 & 214 & 288 & 180 \\
\hline F-test & 3.387 & 4.495 & 1.949 & 1.512 \\
\hline p-value & 0.000 & 0.000 & 0.015 & 0.097 \\
\hline Hausman & 62.330 & -35.068 & 39.751 & 11.147 \\
\hline p-value & 0.000 & 1.000 & 0.002 & 0.888 \\
\hline Chow & 3.233 & 6.710 & 1.756 & 1.679 \\
\hline p-value & 0.000 & 0.000 & 0.031 & 0.076 \\
\hline
\end{tabular}

\begin{tabular}{l|c|c|c|c}
\hline \multicolumn{1}{c|}{ I2 } & EU & EU-old & EU-new & Competitive \\
\hline Coefficient & -0.662 & -0.517 & -0.742 & -0.323 \\
\hline SE Coeff. & 0.002 & 0.004 & 0.003 & 0.004 \\
\hline $\mathrm{R}^{2}$ & 0.455 & 0.528 & 0.471 & 0.305 \\
\hline Obs. & 502 & 216 & 286 & 180 \\
\hline F-test & 7.002 & 6.087 & 3.692 & 1.449 \\
\hline p-value & 0.000 & 0.000 & 0.000 & 0.121 \\
Hausman & 221.337 & 63.589 & 115.873 & 18.338 \\
\hline p-value & 0.000 & 0.000 & 0.000 & 0.434 \\
Chow & 1.597 & 1.401 & 1.630 & 3.066 \\
\hline p-value & 0.025 & 0.156 & 0.053 & 0.001 \\
\hline
\end{tabular}

\begin{tabular}{l|c|c|c|c}
\hline \multicolumn{1}{c|}{ I3 } & EU & EU-old & EU-new & Competitive \\
\hline Coefficient & -0.273 & -0.232 & -0.293 & -0.240 \\
SE Coeff. & 0.001 & 0.002 & 0.002 & 0.002 \\
\hline R $^{2}$ & 0.210 & 0.196 & 0.275 & 0.239 \\
Obs. & 504 & 216 & 288 & 180 \\
\hline F-test & 2.084 & 1.047 & 2.238 & 0.981 \\
p-value & 0.007 & 0.409 & 0.004 & 0.482 \\
Hausman & 78.140 & 22.448 & 48.333 & 29.632 \\
p-value & 0.000 & 0.213 & 0.000 & 0.041 \\
Chow & 1.625 & 1.901 & 1.373 & 0.979 \\
\hline p-value & 0.021 & 0.029 & 0.145 & 0.472 \\
\hline
\end{tabular}




\begin{tabular}{|c|c|c|c|c|}
\hline I4 & EU & EU-old & EU-new & Competitive \\
\hline Coefficient & -0.180 & -0.322 & -0.182 & -0.054 \\
\hline SE Coeff. & 0.001 & 0.002 & 0.001 & 0.001 \\
\hline $\mathrm{R}^{2}$ & 0.206 & 0.511 & 0.235 & 0.134 \\
\hline Obs. & 504 & 216 & 288 & 180 \\
\hline F-test & 1.892 & 5.838 & 2.095 & 1.004 \\
\hline p-value & 0.017 & 0.000 & 0.008 & 0.457 \\
\hline Hausman & 44.974 & 49.987 & 26.230 & 0.877 \\
\hline p-value & 0.000 & 0.000 & 0.095 & 1.000 \\
\hline Chow & 0.823 & 1.342 & 0.516 & 1.648 \\
\hline p-value & 0.736 & 0.186 & 0.949 & 0.084 \\
\hline I5 & $\mathbf{E U}$ & EU-old & EU-new & Competitive \\
\hline Coefficient & -0.395 & -0.322 & -0.433 & -0.383 \\
\hline SE Coeff. & 0.001 & 0.002 & 0.002 & 0.003 \\
\hline $\mathrm{R}^{2}$ & 0.450 & 0.560 & 0.387 & 0.571 \\
\hline Obs. & 504 & 216 & 288 & 180 \\
\hline F-test & 10.890 & 7.347 & 4.952 & 7.818 \\
\hline p-value & 0.000 & 0.000 & 0.000 & 0.000 \\
\hline Hausman & 158.530 & 37.851 & 105.453 & 47.522 \\
\hline p-value & 0.000 & 0.004 & 0.000 & 0.000 \\
\hline Chow & 1.510 & 1.063 & 1.763 & 2.065 \\
\hline p-value & 0.043 & 0.394 & 0.030 & 0.022 \\
\hline
\end{tabular}

\begin{tabular}{l|c|c|c|c}
\hline \multicolumn{1}{c|}{ I6 } & EU & EU-old & EU-new & Competitive \\
\hline Coefficient & -0.239 & -0.400 & -0.222 & -0.220 \\
\hline SE Coeff. & 0.001 & 0.003 & 0.002 & 0.004 \\
\hline R $^{2}$ & 0.180 & 0.335 & 0.179 & 0.172 \\
Obs. & 504 & 216 & 288 & 180 \\
\hline F-test & 1.687 & 1.916 & 1.075 & 1.021 \\
\hline p-value & 0.042 & 0.019 & 0.378 & 0.439 \\
Hausman & 60.005 & 52.647 & 29.657 & 10.078 \\
\hline p-value & 0.000 & 0.000 & 0.041 & 0.929 \\
Chow & 3.852 & 4.170 & 3.572 & 3.300 \\
\hline p-value & 0.000 & 0.000 & 0.000 & 0.000 \\
\hline
\end{tabular}

\begin{tabular}{l|c|c|c|c}
\hline \multicolumn{1}{c|}{ I7 } & EU & EU-old & EU-new & Competitive \\
\hline Coefficient & -0.773 & -0.319 & -0.898 & -0.139 \\
SE Coeff. & 0.002 & 0.004 & 0.004 & 0.001 \\
\hline R $^{2}$ & 0.414 & 0.214 & 0.498 & 0.235 \\
\hline Obs. & 502 & 216 & 286 & 180 \\
\hline F-test & 2.392 & 1.616 & 2.144 & 1.268 \\
\hline p-value & 0.001 & 0.064 & 0.006 & 0.220 \\
Hausman & 276.878 & 31.741 & 209.559 & 21.215 \\
\hline p-value & 0.000 & 0.024 & 0.000 & 0.269 \\
Chow & 1.742 & 3.793 & 1.371 & 4.127 \\
\hline p-value & 0.010 & 0.000 & 0.146 & 0.000 \\
\hline
\end{tabular}

F-Test: Critical value of the joint significance F-test for the year dummies (time fixed effects).

Hausman: Critical value of the Hausman test to select between fixed and random effects.

Chow: Critical value of the structural break Chow test for the two considered sub-periods: 1995-2007 and 2008-2013.

Source: Authors' calculations. 


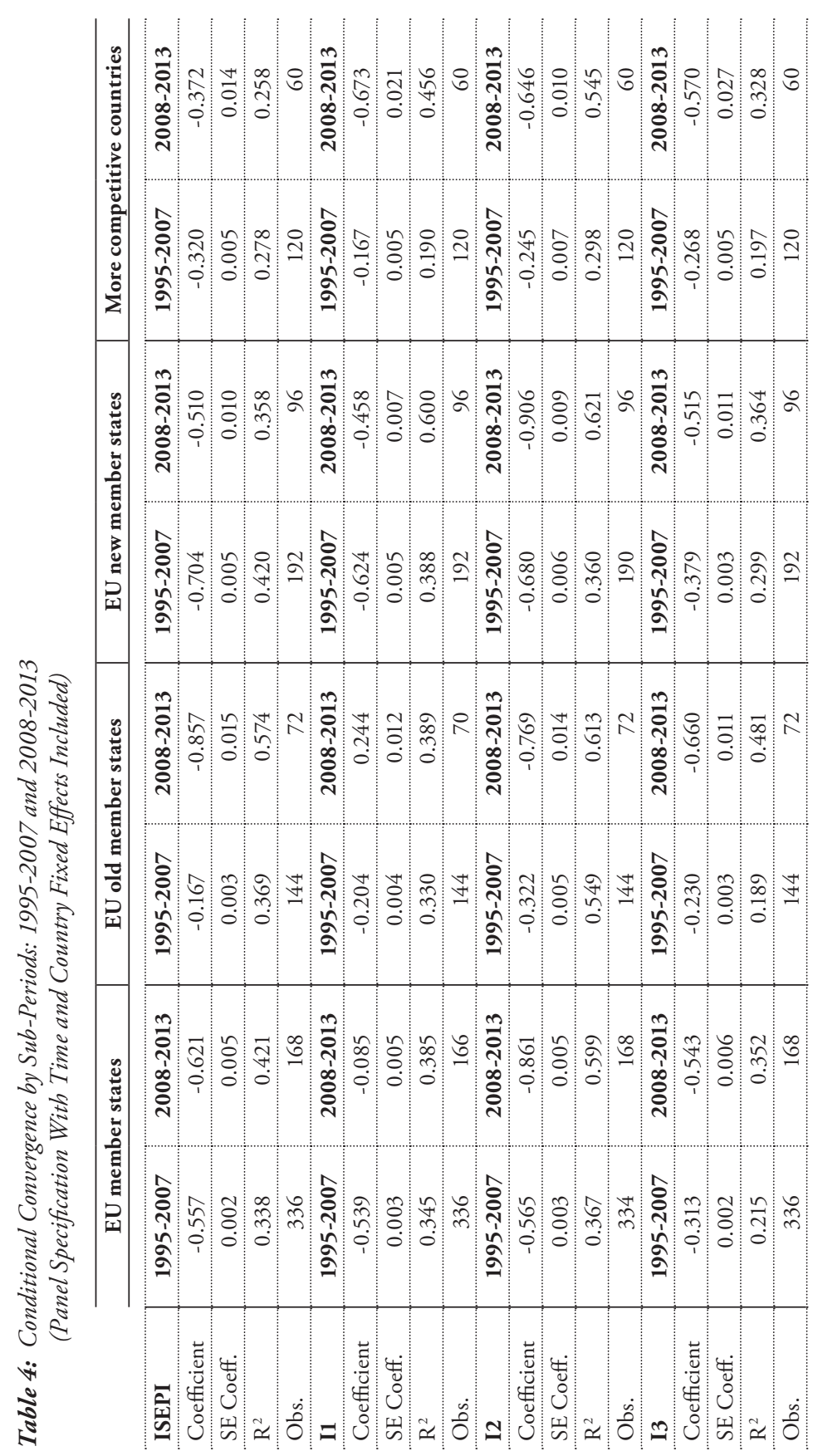




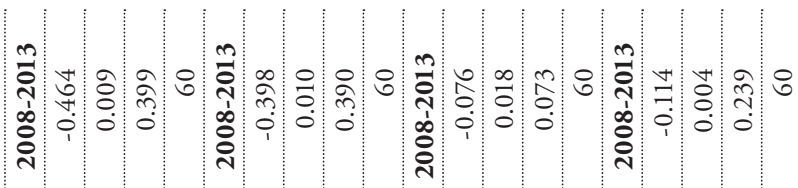

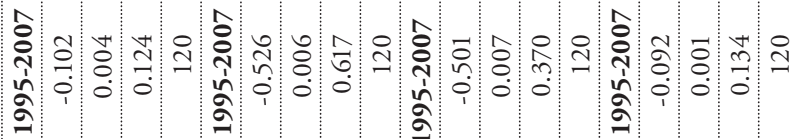

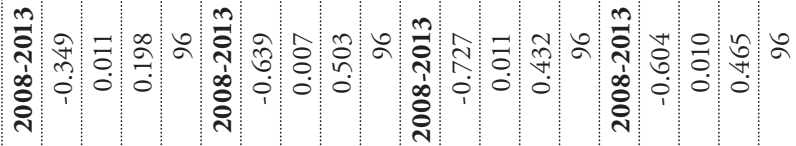

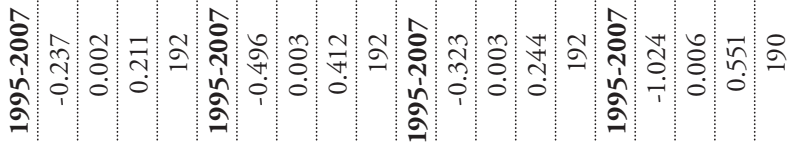

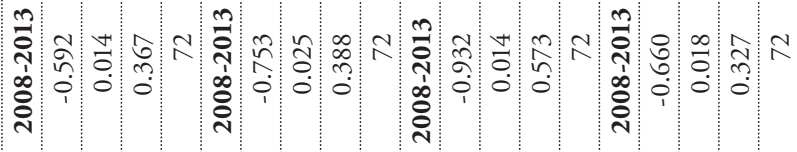

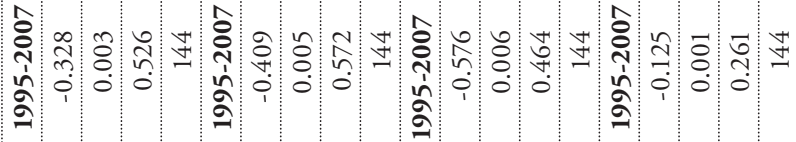

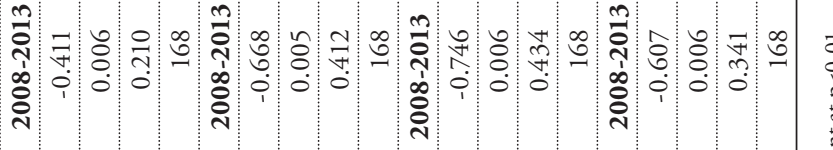

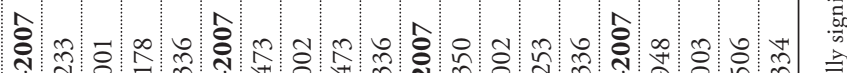

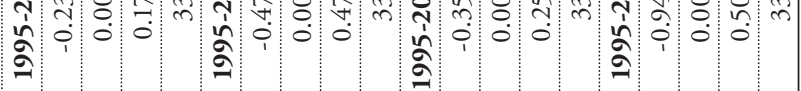

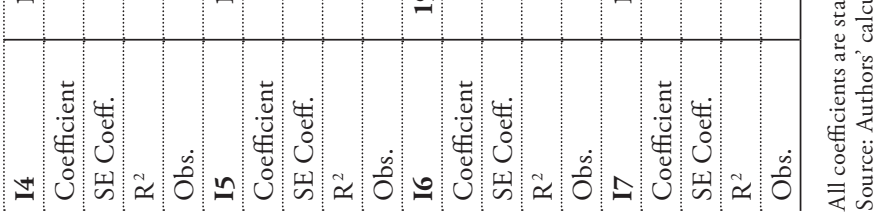


Taking into account this perspective, first interesting conclusion from our results is that the process of conditional convergence is more pronounced in new EU member states, and in the EU as a whole compared to the more competitive economies. A second result from the analysis by sub-periods that deserves our attention is that the speed of conditional convergence has increased during the second period for nearly all indicators and groups of countries. This means that in most recent years, countries are converging to their own steady state faster than before. As far as these states are different due to structural factors that cannot be changed in the short-run, absolute differences between countries could increase in the future. This result is already observed in our cross-sectional analysis.

\section{Final Remarks}

The objective of this paper was to analyze convergence in institutional, social, and macroeconomic conditions in EU member states using a composite indicator that combines information from 51 hard and soft indicators. Our analysis has covered the period 1995-2013, and considered the potential impact of the Great Recession in the different considered dimensions by looking at potential deviations from long-run trends in convergence of two different sub-periods: 1995-2007 and 2008-2013.

With this aim, we have estimated convergence equations for the composite indicator and its seven dimensions considering different country groups. Cross-section and panel convergence regressions found evidence of conditional convergence among EU member states but also limited evidence of unconditional (absolute) convergence over the considered period. These results are in line with previous work. For instance, Rodriguez-Pose and Tselios (2013) found that welfare levels have converged significantly across European regions to different steady states; this result implies that although the gap is diminishing, long-run differences in welfare levels across regions will not even out. According to these authors, convergence in social factors is clearly related to convergence based on 
other structural and institutional factors. Our evidence, which is in line with the results by Savoia and Sen (2013), also shows that institutional quality has grown faster in those countries with initially poor institutions in relative terms.

The analysis by sub-periods also confirms that although the convergence process predicted by the neoclassical model occurs in the long run, different short-run conditions can change the path towards the steady state. In fact, the speed of convergence towards each country's steady state within the different groups of countries considered (i.e., convergence clubs) has increased in different subindexes during the Great Recession. However, it is not clear that these higher transitional growth rates (i.e., higher speed of convergence) are associated with improvements in each individual country (i.e., each steady-state), but they may be associated with short-term corrections and similar policy responses to the common economic shock that the different groups of countries have experienced. The results on conditional convergence also suggest that sharing the same structural characteristics could significantly enhance the 'catch-up' amongst EU member states in the different dimensions. In fact, the evidence for new EU member states is clearly favorable to this hypothesis. 


\section{Annex}

Table A1: Countries included in the ISEPI Index

\begin{tabular}{|c|c|c|}
\hline Countries & & ISO \\
\hline 01 & Angola & AGO \\
\hline 02 & United Arab Emirates & ARE \\
\hline 03 & Argentina & ARG \\
\hline 04 & Armenia & ARM \\
\hline 05 & Australia & AUS \\
\hline 06 & Austria & AUT \\
\hline 07 & Azerbaijan & $\mathrm{AZE}$ \\
\hline 08 & Belgium & BEL \\
\hline 09 & Bulgaria & BGR \\
\hline 10 & Belarus & BLR \\
\hline 11 & Brazil & BRA \\
\hline 12 & Canada & CAN \\
\hline 13 & Switzerland & $\mathrm{CHE}$ \\
\hline 14 & Chile & CHL \\
\hline 15 & China & $\mathrm{CHN}$ \\
\hline 16 & Colombia & COL \\
\hline 17 & Cyprus & CYP \\
\hline 18 & Czech Republic & CZE \\
\hline 19 & Germany & DEU \\
\hline 20 & Denmark & DNK \\
\hline 21 & Algeria & DZA \\
\hline 22 & Egypt & EGY \\
\hline 23 & Spain & ESP \\
\hline 24 & Estonia & EST \\
\hline 25 & Finland & FIN \\
\hline 26 & France & FRA \\
\hline 27 & United Kingdom & GBR \\
\hline 28 & Georgia & GEO \\
\hline 29 & Greece & GRC \\
\hline 30 & Croatia & HRV \\
\hline 31 & Hungary & HUN \\
\hline 32 & Indonesia & IDN \\
\hline 33 & India & IND \\
\hline 34 & Ireland & IRL \\
\hline 35 & Iran, Islamic Republic of & IRN \\
\hline 36 & Israel & ISR \\
\hline 37 & Italy & ITA \\
\hline 38 & Jordan & JOR \\
\hline 39 & Japan & JPN \\
\hline
\end{tabular}

\begin{tabular}{|c|c|c|}
\hline Countries & & ISO \\
\hline 40 & Kazakhstan & KAZ \\
\hline 41 & Kenya & KEN \\
\hline 42 & Korea, Republic of & KOR \\
\hline 43 & Lebanon & LBN \\
\hline 44 & Libya & LBY \\
\hline 45 & Lithuania & LTU \\
\hline 46 & Luxembourg & LUX \\
\hline 47 & Latvia & LVA \\
\hline 48 & Morocco & MAR \\
\hline 49 & Moldova & MDA \\
\hline 50 & Mexico & MEX \\
\hline 51 & Malta & MLT \\
\hline 52 & Malaysia & MYS \\
\hline 53 & Nigeria & NGA \\
\hline 54 & Netherlands & NLD \\
\hline 55 & Peru & PER \\
\hline 56 & Philippines & PHL \\
\hline 57 & Poland & POL \\
\hline 58 & Portugal & PRT \\
\hline 59 & Palestine & PSE \\
\hline 60 & Qatar & QAT \\
\hline 61 & Romania & $\mathrm{ROU}$ \\
\hline 62 & Russian Federation & RUS \\
\hline 63 & Saudi Arabia & SAU \\
\hline 64 & Senegal & SEN \\
\hline 65 & Singapore & SGP \\
\hline 66 & Slovakia & SVK \\
\hline 67 & Slovenia & SVN \\
\hline 68 & Sweden & SWE \\
\hline 69 & Syrian Arab Republic (Syria) & SYR \\
\hline 70 & Thailand & THA \\
\hline 71 & Tunisia & TUN \\
\hline 72 & Turkey & TUR \\
\hline 73 & Tanzania, United Republic of & TZA \\
\hline 74 & Ukraine & UKR \\
\hline 75 & United States of America & USA \\
\hline 76 & Viet Nam & VNM \\
\hline 77 & South Africa & ZAF \\
\hline
\end{tabular}

Source: Authors. 


\section{Literature}

Abreu, Maria, Henri L. F. de Groot and Raymond J.G.M. Florax, 2005, "A Meta-Analysis of Beta-Convergence: The Legendary Two-Percent", Journal of Economic Surveys, 19(3), pp. 389-420. http://dx.doi.org/10.1111/j.09500804.2005.00253.x

Barro, Robert J. and Xavier Sala-i-Martin, 2003, Economic Growth, 2nd edition, Cambridge, MA: MIT Press.

Beyaert, Arielle and José García-Solanes, 2014, "Output Gap and Non-Linear Economic Convergence”, Journal of Policy Modeling, 36(1), pp. 121-135. http:// dx.doi.org/10.1016/j.jpolmod.2013.11.001

Borsi, Mihály Tamás and Norbert Metiu, 2013, "The Evolution of Economic Convergence in the European Union”, Discussion Paper Deutsche Bundesbank No. 28/2013, Frankfurt: Deutsche Bundesbank.

Çolak, Mehmet Selman and Aylin Ege, 2013, "An Assessment of EU 2020 Strategy: Too Far to Reach?”, Social Indicators Research, 110(2), pp. 659-680. http://dx.doi.org/10.1007/s11205-011-9950-2

European Commission, 2014, Taking Stock of the Europe 2020 Strategy for Smart, Sustainable and Inclusive Growth, Communication from the Commission to the European Parliament, the Council, the European Economic and Social Committee and the Committee of the Regions, Brussels: European Commission, http://ec.europa.eu/europe2020/pdf/europe2020stocktaking_en.pdf (accessed November 13th, 2014).

Giambona, Francesca and Erasmo Vassallo, 2014, "Composite Indicator of Social Inclusion for European Countries", Social Indicators Research, 116(1), pp. 269-293. http://dx.doi.org/10.1007/s11205-013-0274-2 
Gill, Indermit S. and Martin Raiser, 2012, "Golden Growth : Restoring the Lustre of the European Economic Model, Main Report Vol. 2", The World Bank Working Paper, No. 68168, Washington, DC: The World Bank. http://documents.worldbank.org/curated/en/2012/04/16234385/goldengrowth-restoring-lustre-european-economic-model (accessed November 13th, 2014).

Liargovas, Panagiotis G. and Georgios Fotopoulos, 2009, "Socioeconomic Indicators for Analyzing Convergence: The Case of Greece: 1960-2004”, Social Indicators Research, 93(2), pp. 315-330. http://dx.doi.org/10.1007/s11205-0089319-3

López-Tamayo, Jordi, Raul Ramos and Jordi Suriñach-i-Caralt, 2014, "An Institutional, Social and Economic Performance Index (ISEPI) with an application to the European Neighbourhood Policy", AQR Working Paper, No. 2014/12, Barcelona: IREA.

Niroomand, Farhang and Edward Nissan, 2007, "Socio-Economic Gaps Within the EU: A Comparison", International Advances in Economic Research, 13(3), pp. 365-378. http://dx.doi.org/10.1007/s11294-007-9092-0

Rodríguez-Pose, Andrés and Vassilis Tselios, 2013, "Toward Inclusive Growth: Is There Regional Convergence in Social Welfare?”, International Regional Science Review, forthcoming. http://dx.doi.org/10.1177/0160017613505201

Savoia, Antonio and Kunal Sen, 2012, "Do We See Convergence in Institutions? A Cross-Country Analysis", Development Economics and Public Policy Working Paper Series, No. 33/2012, Rochester, NY: Social Science Research Network.

Wu, Po-Chin, Chiung-Wen Fan and Sheng-Chieh Pan, 2014, "Does Human Development Index Provide Rational Development Rankings? Evidence from Efficiency Rankings in Super Efficiency Model", Social Indicators Research, 116(2), pp. 647-658. http://dx.doi.org/10.1007/s11205-013-0285-z 